\title{
Design and evaluation of a two-section canopy shaker with variable frequency for mechanical harvesting of citrus
}

\author{
Yingjun $\mathrm{Pu}^{1,3}$, Arash Toudeshki ${ }^{2,3}$, Reza Ehsani ${ }^{2,3^{*}}$, Fuzeng Yang ${ }^{1 *}$ \\ (1. College of Mechanical and Electronic Engineering, Northwest A\&F University, Yangling 712100, Shaanxi, China; \\ 2. School of Engineering, University of California, Merced, CA 95343, USA; \\ 3. Citrus Research \& Education Center, Institute of Food and Agricultural Sciences, University of Florida, Lake Alfred, FL 33850, USA)
}

\begin{abstract}
Canopy shaking is one of the most commonly used techniques for mechanical harvesting of citrus fruits in orange juice industry. However, tree damage and low harvesting efficiency are the top concerns of growers in adopting the existing harvesting equipment on a large scale. The purpose of this research was to develop a novel canopy shaking system to minimize tree damage and maximize fruit removal for mechanical citrus harvesting. In this study, a two-section canopy shaker composing of top and bottom shaking systems mounted on two rotating drums was proposed and developed. It was configured with two sets of flexible bow-shaped shaking rods in a staggered distribution, which can shake the top and bottom zones of the tree canopy independently. The shaking system was designed based on a linked crank-rocker mechanism. Kinematic simulation analysis was conducted to verify the quick return characteristics and differential properties of this mechanism. Vibration test showed that the frequency of the shaking rod could be adjusted within a range of 1.1-8.8 Hz related to hydraulic motor speeds. The field tests of the shaking system with an average frequency of $4.7 \mathrm{~Hz}$ achieved a fruit removal percentage of $82.6 \%$ and tree damage rate of $5.4 \%$ under a tractor speed of $3 \mathrm{~km} / \mathrm{h}$. By contrast, the combined shaking frequency of $4.7 \mathrm{~Hz} \& 4.1 \mathrm{~Hz}$ of the canopy shaker produced less tree damage with a percentage of $3.9 \%$. This study indicated that the two-section canopy shaker with an optimized frequency combination could be adaptable to the different zones of the tree canopy, and obtain lower tree damage and higher fruit removal percentage.
\end{abstract}

Keywords: two-section canopy shaker, crank-rocker mechanism, variable frequency, fruit removal percentage, tree damage rate, citrus mechanical harvesting

DOI: $10.25165 /$ j.ijabe.20181105.4445

Citation: Pu Y J, Toudeshki A, Ehsani R, Yang F Z. Design and evaluation of a two-section canopy shaker with variable frequency for mechanical harvesting of citrus. Int J Agric \& Biol Eng, 2018; 11(5): 77-87.

\section{Introduction}

According to the Food and Agriculture Organization of the United Nations (FAOSTAT, 2016), around 131 million metric tons of citrus fruits are produced in the world $(57 \%$ oranges, $26 \%$ tangerines, $11 \%$ lemons, $6 \%$ grapefruits ${ }^{[1]}$. In the United States, 'Valencia' oranges account for the majority of the citrus crop, including half of Florida's total citrus production, and is the most well-known variety for orange juice ${ }^{[2]}$. In spite of the large efforts in the development of mechanical harvesting systems for the orange juice industries, manual harvesting is still the main harvesting method used, which is very labour intensive and costly ${ }^{[3,}$ 4]. As a result, attempts to reduce harvesting costs are an on-going challenge for fruit crop producers ${ }^{[5]}$. With the development of the mechanized harvesting techniques, mechanical shaking systems

\section{Received date: 2018-06-01 Accepted date: 2018-08-11}

Biographies: Yingjun $\mathrm{Pu}, \mathrm{PhD}$ candidate, research interests: agricultural mechanization and automation, Email: puyj1987@163.com; Arash Toudeshki, $\mathrm{PhD}$, Post-doctorate, research interests: applied electronics in physics and robotics, Email: arashtoudeshki@gmail.com.

*Corresponding author: Fuzeng Yang, $\mathrm{PhD}$, Professor, research interests: agricultural mechanization and automation. P.O. Box 16, Northwest Agriculture and Forestry University, No. 22 Xinong Road, Yangling 712100, Shaanxi, China. Tel: +86-29-87092391, Email: yfz0701@163.com; Reza Ehsani, PhD, Professor, research interests: mechanical harvesting machines and robots. University of California, Merced, 5200 N. Lake Road, SE2-282, Merced, CA 95343, United States. Tel: +1-209-228-3613, Fax: +1-209-228-4047, Email: rehsani@, ucmerced.edu. can effectively detach fruits which have the potential to achieve less expenditure and higher efficiency for mass removal of fruits ${ }^{[6]}$.

Since the early $1960 \mathrm{~s}^{[7]}$, technologies employing a method of shaking in mechanical harvesters have been widely studied and significantly enhanced to replace human labour in citrus harvesting operations. Shaking mechanisms are the most commonly investigated methods for mechanical harvesting of tree fruit crops, such as oranges ${ }^{[8-11]}$, olives ${ }^{[12-14]}$, apples ${ }^{[15]}$, coffee beans ${ }^{[16]}$, grapes $^{[17]}$, blueberries ${ }^{[18]}$ and other fruits, but it's easy to cause the fruit to bruise, which affect its quality. Therefore, mechanical shaking systems are mainly used for the harvesting of industrial fruits without consideration of bruises, such as juice, oil or wine. At present, canopy shaker and trunk shaking systems are the main types of harvesting machines commercially used in orchard for juice production ${ }^{[8,9]}$. Both harvesting systems can potentially increase the labour productivity by 5 to 15 times than that of hand picking and decrease the unit harvesting cost by $50 \%$ or more ${ }^{[19]}$. Moreover, mass harvesting based on a canopy shaking system can obtain a harvesting rate 2-3 times higher than that investigated with trunk shakers because of its continuously harvesting process ${ }^{[9]}$.

In particular, canopy shaker is the most common type of fruits harvester that is equipped with a catch frame and conveyer system, which continuously shakes the tree canopy at a certain frequency to detach fruits. For example, a continuous canopy shaker (OXBO International Corporation, Byron, NY, USA) with two self-propelled single drum shakers and two catch frame systems that operated simultaneously on both sides of the tree canopy for commercial citrus harvesting was presented by former 
researchers ${ }^{[9,20,21]}$. A self-propelled canopy grape harvester (VL6060 Braud, Morigny-Champigny, France) comprising a beater installed with 14 mounting bow-shaped rods (7 rods for each side), a conveyor belt transport system and a cleaning apparatus was developed to harvest grapes for the wine industry ${ }^{[17,22]}$. These types of continuous canopy shaking systems are currently being used for commercial harvesting of citrus or grapes on a small scale and have gained popularity and acceptance from growers, because they have greatly improved the fruit harvesting efficiency ${ }^{[23,24]}$, but there is also a great concern among growers regarding the structural damage to the tree canopy and harvesting yield of the following year ${ }^{[25]}$. Coppock ${ }^{[26]}$ reported that trees of 'Valencia' oranges that were harvested by a mechanical shaker may experience more than a $50 \%$ yield loss in the subsequent harvesting season. A better developing trend of mechanical shaking systems should concentrate on minimal tree damage as well as higher fruit removal efficiency.

The current canopy shaking mechanisms have wheel-hub type ${ }^{[9,21,28]}$ and drum-type ${ }^{[19,27]}$ shakers, which strike the tree canopy with the same shaking parameters controlled by the operator. However, canopy shaking for fruit detachment is affected by several factors, such as the fruit characteristics (mass, volume, maturity, peduncle length, peel firmness), the mechanical and geometrical characteristics of the tree (density, form, canopy dimension and branch distribution), and the characteristics of the forcing vibration (frequency, amplitude and duration) ${ }^{[24,38,41]}$. In principle, a canopy shaking system employs a particular vibration mechanism to transmit kinetic energy to fruiting branches through a series of shaking rods with a certain frequency and amplitude for generating an inertial force on the fruit-stem interface. Then, the forced vibration will complete the separation process to detach fruits when the inertial force of the fruit is greater than the adhesion strength of the detachment force in the weakest point ${ }^{[29,30]}$. Therefore, due to the random spatial distribution and different stiffness characteristics of the tree limbs, it is inevitable to detach fruits, loose leaves and break limbs simultaneously when shaking the tree canopy.

On account of the irregular growth of the branches and the uneven distribution of the fruits, Whitney and Wheaton ${ }^{[31]}$ demonstrated that the upper parts of the tree canopy had a greater percentage of oranges, which was a priority area for a mechanical harvesting system. Furthermore, several researchers have investigated canopy shakers striking different zones of the tree canopy with adjustable shaking parameters to prove this consideration. For example, a double-spiked-drum canopy shaker was developed with two vertical shaking shafts equipped with top and bottom whorls producing a shaking frequency of $4-5 \mathrm{~Hz}$ and an average fruit removal percentage from $71 \%$ to $91 \%{ }^{[10,32]}$. Additionally, Gupta et al. $^{[33]}$ using numerical methodology, manifested the different configuration and properties of the primary limbs in the top, middle, and bottom zones of a citrus tree canopy. Based on this previous study, Gupta et al. ${ }^{[24]}$ proposed the idea of adaptive shaking of the tree canopy by finite element analysis and computer-aided optimization techniques to improve a citrus continuous canopy shaker based on the configuration of limbs and the distribution of fruits. They found that the optimized shaking rod configuration of the bottom, middle and top section of the canopy shaker produced a prominent reduction in tree damage when shaking with different frequencies and amplitudes. Their exploratory work suggested that the canopy shaking system could minimize tree damage by imparting a variable shaking frequency and amplitude to the tree canopy based on the fruit spatial distribution and primary limb configuration. Hence, the adaptation of the shaking system on different zones of the tree canopy is a necessary starting point to develop an efficient harvesting technique with capability to reduce tree damage.

The main purpose of this study was to design and evaluate a two-section canopy shaker with variable frequency for adapting to the irregular distribution of branches and fruits in order to minimize tree damage while maximizing fruit removal. The specific objectives of this research were: (1) to design and develop a novel canopy shaking mechanism that can be operated at variable frequencies; (2) to investigate a reasonable shaking rod distribution for a better adaptable performance to reduce tree damage; and (3) to obtain the optimal operation parameters by evaluating the performance of the designed canopy shaker.

\section{Design and prototyping of the two-section canopy shaking system}

\subsection{Tree canopy measurement}

The dimension of the shaking system should be based on the tree canopy size. In this study, 59 tree samples in seven lines were selected from 12-year-old 'Valencia' citrus trees with an east-west orientation. The medium-size citrus trees were planted with a $6 \mathrm{~m}$ row spacing and a $4 \mathrm{~m}$ in-row tree spacing. The test area used in this investigation was located in an orchard of the Citrus Research \& Education Center (CREC) in Lake Alfred, Florida, USA $\left(28^{\circ} 06.344^{\prime}-28^{\circ} 06.366^{\prime} \mathrm{N}, 81^{\circ} 42.977^{\prime}-81^{\circ} 42.899^{\prime} \mathrm{W}\right)$ (Figure 1a). The upper parts of the tree canopy containing more than $60 \%$ of the fruit yield should be a main area for the mechanical harvesting system ${ }^{[24,31]}$. Thus, we divided citrus tree canopy into two sections of the top and bottom zones from the largest horizontal canopy diameter. The canopy dimension parameters of the citrus trees were measured using band tape with resolution of $0.1 \mathrm{~mm}$, respectively, as shown in Figure $1 \mathrm{~b}$.
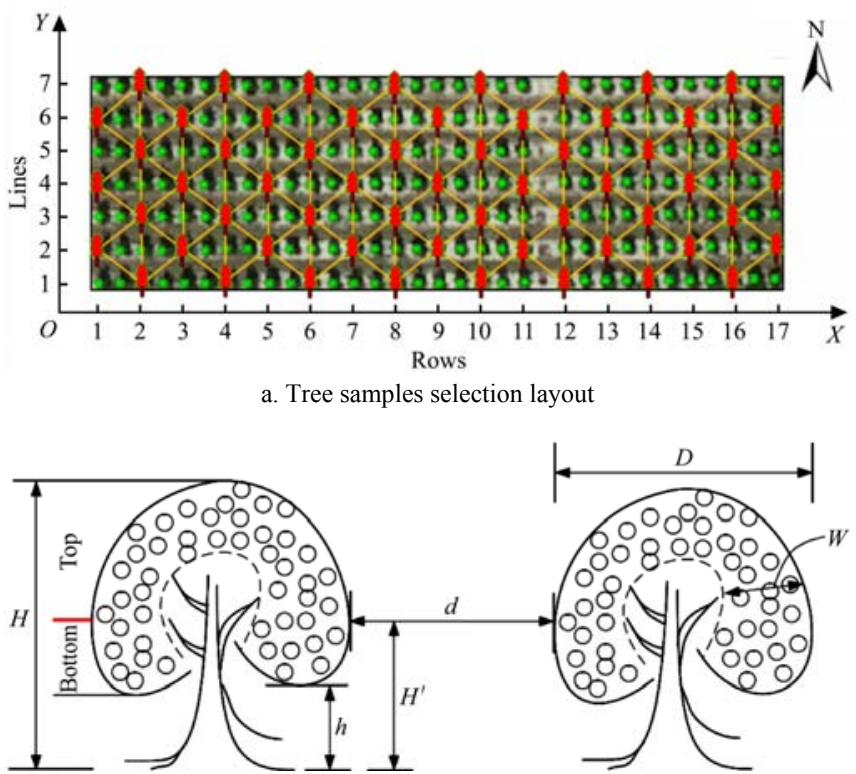

b. Schematic sketch of tree canopy measurement

Note: $H$ is the height of the tree; $H^{\prime}$ is the height from the ground to the largest horizontal canopy diameter; $h$ is the height from the ground to the bottom of the canopy; $D$ is the largest horizontal diameter of the tree canopy; $d$ is the dimension of the two tree canopies between adjacent lines; $W$ is the depth of the fruit distribution area where are from outside edge to the inner space without fruits.

Figure 1 Schematic illustration of canopy size measurement 
To increase the accuracy of the measurement, the parameters of the tree canopy size were measured multiple times. Specifically, $H^{\prime}, h$ and $W$ were measured 4 times around each tree sample; $D$ was measured two times through the tree canopy with intersecting direction. Table 1 lists the measured parameters of the tree canopy with mean values and standard deviations (SD). Obviously, the canopy height for this citrus orchard was approximately $1.89 \mathrm{~m}$ (i.e., $H-h$ ).

Table 1 Measured canopy dimension parameters $(n=59)$

\begin{tabular}{ccc}
\hline Parameters & Range of dimension $/ \mathrm{m}$ & Mean values and $\mathrm{SD} / \mathrm{m}$ \\
\hline$H$ & $1.78-3.0$ & $2.47 \pm 0.24$ \\
$H^{\prime}$ & $1.05-1.63$ & $1.34 \pm 0.14$ \\
$h$ & $0.32-0.91$ & $0.58 \pm 0.12$ \\
$D$ & $2.01-3.52$ & $2.94 \pm 0.35$ \\
$d$ & $2.74-4.01$ & $3.24 \pm 0.30$ \\
$W$ & $0.64-1.23$ & $1.03 \pm 0.11$ \\
\hline
\end{tabular}

\subsection{Conceptual design based on crank-rocker mechanism}

Generally, canopy shaking systems employ several shaking rods penetrating to the tree canopy and striking the branches with a certain frequency and amplitude produced by a reciprocating vibration mechanism. In this study, a linked crank-rocker mechanism was designed based on the reciprocating motion as shown in Figure 2. It was driven by a single crank $(O A)$ which actuated two rockers, making their movement synchronized. The extension bars $(M P \& N Q)$ were used as shaking rods mounted on the end of the rockers. Hence, the crank could drive the front and rear shaking rods swinging simultaneously. Besides, the shaded sector area with an angle of $\varphi$ is the moving range of the shaking rod.

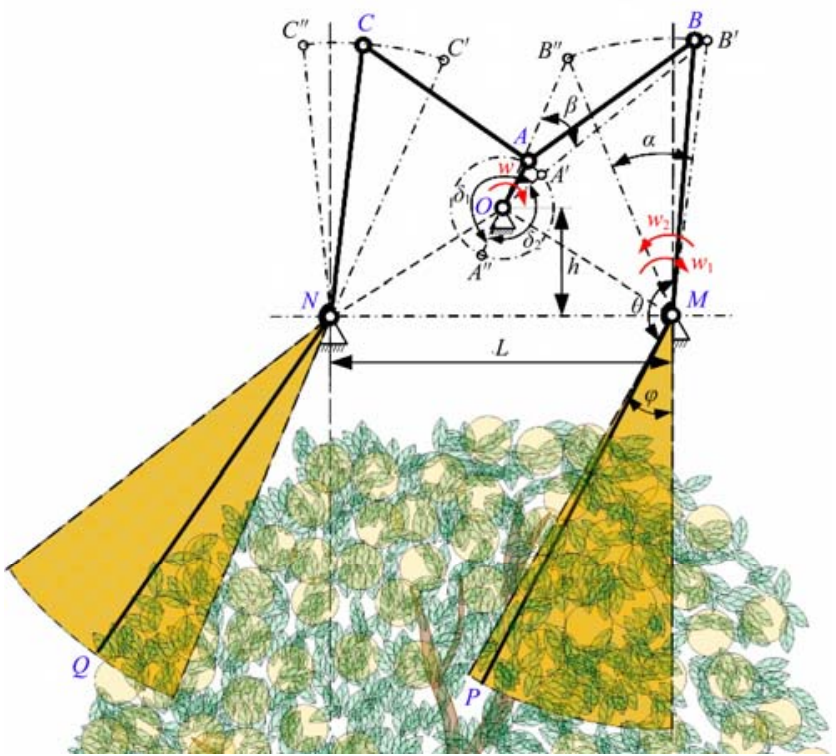

Note: $O A$ is the crank; $A C$ and $A B$ are the connecting rods; $N C$ and $M B$ are the rocking bars; $M P$ and $N Q$ are the shaking rods; $\alpha$ is the swing angle of the rocker; $\beta$ is the crank angle between the two extreme positions; $\delta_{1} \& \delta_{2}$ is the intersection angle of the crank.

Figure 2 Schematic sketch of the linked crank-rocker mechanism

In this linked crank-rocker mechanism, the rotation of the rocker from $M B^{\prime \prime}$ to $M B^{\prime}$ was defined as the operating stroke with angular velocity of $\omega_{1}$, and the rotation of the crank from $M B^{\prime}$ to $M B^{\prime \prime}$ was set as the return stroke with angular velocity of $\omega_{2}$. According to the quick-return characteristics of the crank-rocker mechanism, the angular velocity of the operating stroke is less than that of the return stroke. The shaking rod $M P$ is mounted on the rocker $M B$ which rotates in the opposite direction swinging through the same hinge. Accordingly, the shaking rod swings quickly to strike the canopy when the rocker is on the return stroke. To summarize, this shaking mechanism utilized the quick return characteristics to enhance the external vibration of the shaking rod and increase the shaking efficiency on the tree canopy.

Basically, a crank-rocker mechanism is a type of planar four-bar linkage mechanism where the length of the linkages meets the following Grashof's criteria as given in Equation (1), and the bar adjacent to the shortest linkage has a fixed mount ${ }^{[34]}$.

$$
l_{\max }+l_{\min } \leq l_{1}+l_{2}
$$

where, $l_{\max }$ is the length of the longest linkage; $l_{\min }$ is the length of the shortest linkage; $l_{1}$ and $l_{2}$ are the length of the other two linkages.

Take the four-bar linkage $(O A, A B, B M$ and $O M)$ as an example shown in Figure 2, the dimension of the crank-rocker mechanism was designed and calculated. According to the mechanism design and actual condition, the dimensions of $L$ and $h$ were $762 \mathrm{~mm}$ and $244 \mathrm{~mm}$, respectively. Thus, the distance between point $O$ and $M$ can be calculated by Equation (2). In addition, $a, b, c, d$ were assumed as the dimension of $O A, A B, M B$ and $O M$, respectively. The geometrical relationship of the crank-rocker mechanism was represented by Equation $(3)^{[35]}$.

$$
\begin{gathered}
l_{O M}=\sqrt{h^{2}+\frac{L^{2}}{4}} \\
c^{2} \sin ^{2} \frac{\alpha}{2}=a^{2} \cos ^{2} \frac{\beta}{2}+b^{2} \sin ^{2} \frac{\beta}{2}
\end{gathered}
$$

where, $l_{O M}$ is the dimension between point $O$ and $M$, namely $d$, mm; $a, b, c$ were defined as the length of $O A, A B, M B$, respectively, mm; $\alpha$ is the swing angle of the rocker, $\left(^{\circ}\right) ; \beta$ is the crank angle between the two extreme positions, $\left(^{\circ}\right)$.

In order to ensure the shaking system striking the tree canopy with greater transmission performance, the coefficient of travelling speed variation was determined with 1.3 , thus the crank angle between the two extreme positions $(\beta)$ is $23.48^{\circ}$. On the basis of the constraint conditions and geometrical relationship, the parameters of this shaking mechanism was designed and calculated as given in Table 2. To minimize impact-induced tree damage, one method is to reduce the contact area between the shaking rod and the tree canopy. According to the swing angle of the rocker about $30^{\circ}$, the inclined angle $\theta$ between the shaking rod (MP or $N Q$ ) and the rocker $(M B$ or $N C)$ was fixed at $150^{\circ}$ so that the potential relative position of the shaking rod could not exceed the deepest location of the tree canopy as shown in Figure 2.

Table 2 Parameters of the linked crank-rocker mechanism

\begin{tabular}{cccc}
\hline Components & Length/mm & Parameters & Value \\
\hline$O A$ & 114 & $L$ & $762 \mathrm{~mm}$ \\
$A C \& A B$ & 400 & $h$ & $244 \mathrm{~mm}$ \\
$N C \& M B$ & 525 & $\alpha$ & $30.51^{\circ}$ \\
$O M$ & 452 & $\beta$ & $23.48^{\circ}$ \\
$M P \& N Q$ & 1100 & $\theta$ & $150^{\circ}$ \\
\hline
\end{tabular}

\subsection{Simulation analysis of the shaking mechanism}

A 3D model of the shaking mechanism was created in SolidWorks ${ }^{\circledR}$ (Dassault Systèmes SolidWorks Corp., Waltham, MA, USA) according to the designed principal parameters listed in Table 2. The 3D model consisting of sprocket wheel, flywheel, connecting rods, rocking bars, drums and shaking rods, was imported in the 'ViewFlex' module of MSC Adams 2013 (MSC Software Corporation, Newport Beach, CA, USA) for dynamic simulation analysis as shown in Figure 3. The sprocket wheel 
was set up with a rotational joint motion at the actuating speed of $120\left(^{\circ}\right) / \mathrm{s}$ to drive the linked crank-rocker mechanism. To increase the simulating speed in Adams, the model of the shaking mechanism was simplified by removing some accessory parts with little mass such as bolts, bearings, and hinge pins. After the pre-processing of the constraint, motion and material property, the simulation was conducted with $10 \mathrm{~s}$ duration and 100 steps. Finally, the angular velocity and acceleration along with the direction of the shaking rod vibration were analysed and plotted in the Postprocessor of the ADAMS Software.

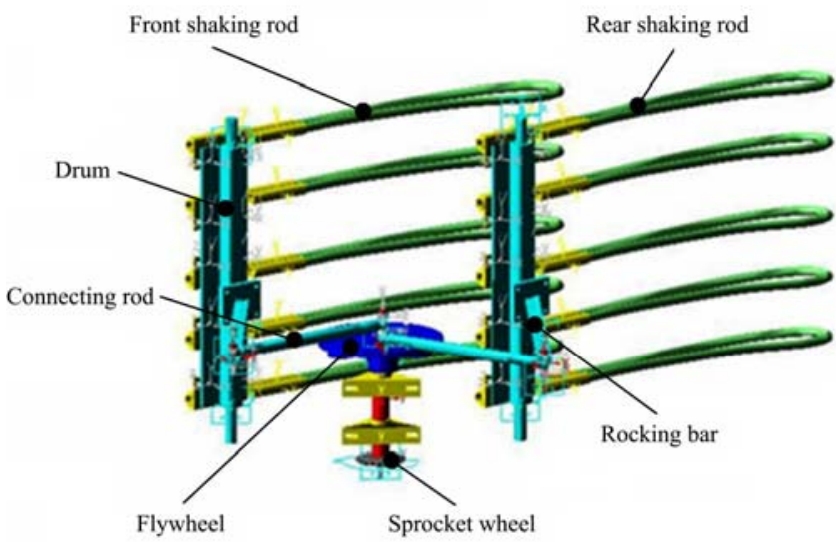

Figure 3 Simulation model of the shaking mechanism in ADAMS

\subsection{Prototyping of the two-section canopy shaking system}

\subsubsection{Prototype fabrication of the shaking system}

Before fabricating the canopy shaker, a virtual prototype of the shaking system was built in SolidWorks according to the principal design parameters (Figure 4a). After interference checking and dynamic simulation of the shaking mechanism in the SolidWorks environment, a shaking system that could perform continuous canopy shaking was designed and manufactured in the engineering workshop of the Citrus Research \& Education Center (CREC) of University of Florida in Lake Alfred, Florida (Figure 4b). Based on previous studies on sectionalized vibration, this canopy shaker had a top and a bottom shaking system which could be operated separately. To provide the requisite functions of frequency adjustment and positioning operation, the shaking system consisted of the following eight main components: (1) a flywheel; (2) a hydraulic motor with a displacement of $80 \mathrm{~cm}^{3}$ per rotation (Char-Lynn 158-2010-001, Eaton Hydraulics Group, Eden Prairie, MN, USA); (3) a hydraulic cylinder with a stroke of $812.8 \mathrm{~mm}$; (4) an operating handle; (5) a hydraulic flow control valve (Sun Hydraulics Corporation, Sarasota, FL, USA); (6) a support frame; (7) Carrying rollers and guide rollers; (8) several shaking rods.

2.4.2 Main technical parameters of the canopy shaker

The whole shaking system was mounted on the head of a $74 \mathrm{~kW}$ standard OXBO 3200 pick-up machine (model 4045TF270, John Deere Power Systems, Waterloo, IA, USA) as graphically represented in Figure 5. The actual height of the top and bottom shaking system were $1.15 \mathrm{~m}$ and $0.67 \mathrm{~m}$, respectively, close to the relative top and bottom canopy height. A type of bow-shaped flexible shaking rod (material: Polyamide Nylon 12 (PA)) was employed in this study with a length of $914.4 \mathrm{~mm}$ and a diameter of $25.4 \mathrm{~mm}$ for the canopy shaking ${ }^{[36]}$. The maximum depth of the shaking rod inserting in the tree canopy reached to $1.1 \mathrm{~m}$ when the shaking rod was moving to the extreme position. The total dimension of the shaking head is the length of $1.98 \mathrm{~m}$, the width of $3 \mathrm{~m}$ and the height of $2.54 \mathrm{~m}$. In addition, this machine provides a slow speed $(<7 \mathrm{~km} / \mathrm{h})$ for mechanical harvesting and a high speed from $7 \mathrm{~km} / \mathrm{h}$ to $15 \mathrm{~km} / \mathrm{h}$ for road driving.

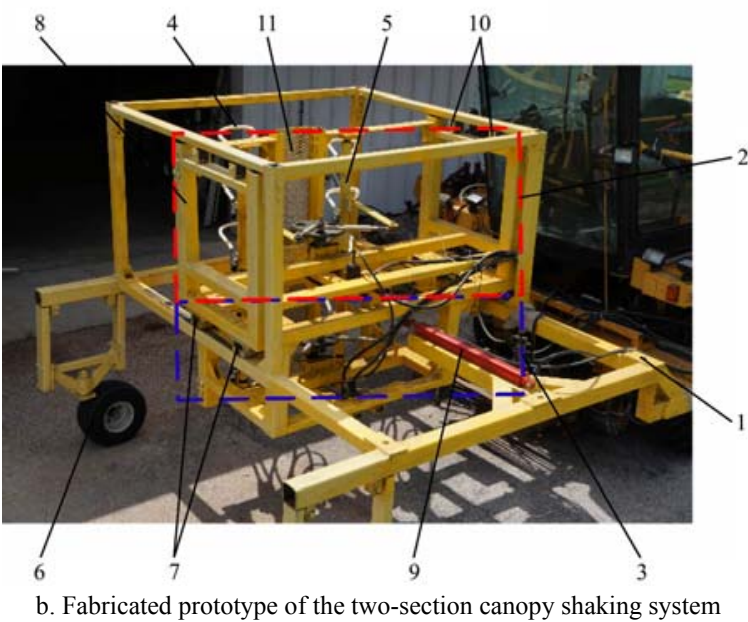

1. Vehicle frame 2. Top shaking system 3. Bottom shaking system 4. Shaking rod 5. Rotating plate 6. Universal wheel 7. Carrying roller 8. Body frame 9. Hydraulic cylinder 10. Upper guide roller 11. Protection grid 12 . Side guide roller 13 . Hydraulic motor 14. Rocker 15. Adjustable connecting rod 16. Chain 17. Flywheel

Figure 4 Prototype fabrication of the shaking system

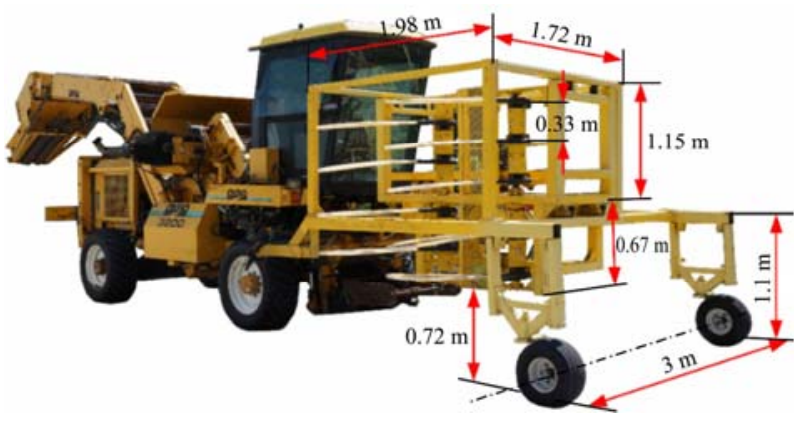

Figure 5 Actual dimensions of the fabricated prototype

\subsubsection{Working principle of the shaking system operation}

The rotational motion of the flywheel as a crank was driven by a hydraulic motor through chain transmission with an adjustable rotation speed. The reciprocating motion of the shaking rods was actuated by the rocking bar of the crank-rocker mechanism through an adjustable connecting rod. The shaking rod could be inserted into the tree canopy when the whole shaking system was pushed out by a hydraulic cylinder. Then, the shaking rods with a certain frequency range stroke one side of the tree canopy to remove fruits along with the canopy shaker moving forward. The frequency could be easily adjusted by controlling the speed of the hydraulic 
motor through a flow control valve. The motion amplitude could also be changed by utilizing the adjustable connecting rod. Finally, the total shaking systems along with the tractor could continuously strike the tree canopy side by side for fruits harvesting.

\section{Performance evaluation of the canopy shaker}

\subsection{Field trial preparation}

The variety of the citrus trees used in this field tests was 'Valencia' orange. To note, 'Valencia' is a late-season variety that bears both mature fruits and immature fruitlets during the entire harvesting season. Mechanical harvesting could result in a significant reduction in the following year's yield because the inertial force may simultaneously detach the mature fruits and the immature fruitlets ${ }^{[37]}$. Therefore, in order to diminish the yield loss of the subsequent year, the harvesting date is very important for citrus harvesting. Roka et al. ${ }^{[9]}$ recommended that the harvest period should occur before the time when the diameter of the emerging fruitlets was less than $25.4 \mathrm{~mm}$, which is typically by early May. For this reason, all field trials were carried out in March and April during 2017 harvesting season. Before harvesting, all the trashes under the tree canopies were swept by raking to reduce uncorrelated error in measuring the fruit removal and tree damage level.

\subsection{Vibration performance of the shaking system}

Frequency and amplitude of the shaking system are the main parameters that need to be considered in mechanical harvesting of fruit ${ }^{[41]}$. In this study, the flywheel actuated by hydraulic motor was operated through chain transmission using seven rotational speeds corresponding with seven frequencies, as shown in Table 3. Actually, the rotational speeds are average values because of the fluctuant but not constant rotational speed displayed by a developed speed monitoring system, which was calibrated by a Digital Hand-Tachometer (CDT-2000HD, Electromatic Equipment Co., Cedarhurst, NY, USA) with accuracy of $0.02 \%$ and a resolution of $0.01 \mathrm{r} / \mathrm{min}$. The vibration performance tests of the shaking system under different hydraulic motor speeds were conducted using a data acquisition system with multi-channel accelerometer and data logger.

Table 3 Parameters of the hydraulic motor operation

\begin{tabular}{cccccccc}
\hline Items & \multicolumn{7}{c}{ Values } \\
\cline { 5 - 9 } $\begin{array}{c}\text { Hydraulic motor } \\
\text { speed/r.r.min }\end{array}$ & 60 & 80 & 100 & 120 & 140 & 160 & 180 \\
Frequency/Hz & 1.0 & 1.3 & 1.7 & 2.0 & 2.3 & 2.7 & 3.0 \\
\hline
\end{tabular}

In order to measure the acceleration variation of the shaking system accurately, ten triple-axis accelerometers were separately attached to the end of ten shaking rods as shown in Figure 6. Then, the acceleration data was processed to acquire the frequency and amplitude variation through analysing the algorithm in MATLAB environment (R2010b, Version 7.11.0.584, Natick, MA, USA). The algorithm was developed for processing data, including resultant acceleration calculation, acceleration peak counting, data points, frequency counter, fitting and statistical data analysis expounded by $\mathrm{Pu}$ et al. ${ }^{[36]}$. Finally, the mean values and standard deviations (SD) of the frequency and acceleration amplitude were obtained by statistical analysis. The motion frequency of the shaking rod was defined as an inherent frequency depending on the certain hydraulic motor speed. The shaking displacement was mainly determined by the designed structure, but it was also affected by the elastic deformation of the flexible shaking $\operatorname{rod}^{[36]}$, which was difficult to accurately measure in this study.

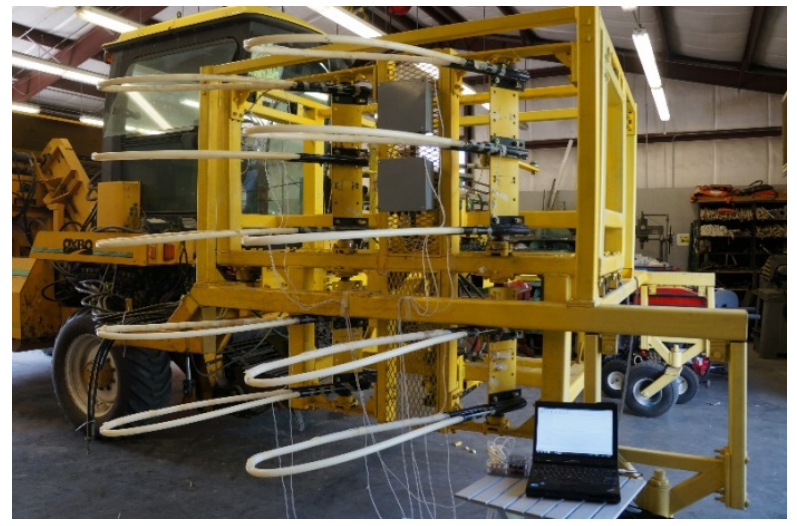

Figure 6 Acceleration test of the shaking rod

\subsection{Fruit removal efficiency and tree damage assessment}

Based on the purpose of this study, the harvesting performance of the new designed canopy shaker was evaluated mainly on fruit detachment efficiency and tree damage assessment through field trials (Figure 7). In this study, the hydraulic motor speed, which produces the variable shaking frequency, is the main factor that could affect the fruit removal efficiency and tree damage.

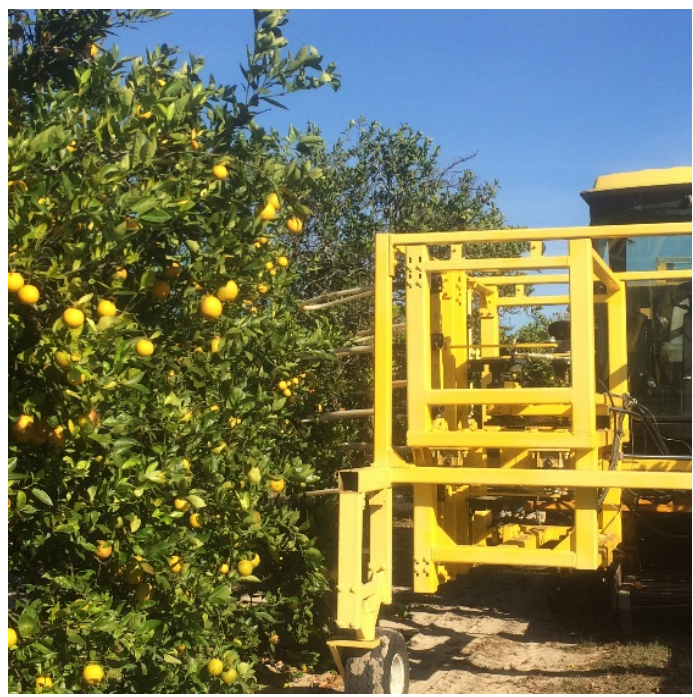

Figure 7 Field harvesting tests of the prototype

Five sets of field tests were conducted on five rows under different shaking frequencies. The initial motor rotating speed was set at $100 \mathrm{r} / \mathrm{min}, 120 \mathrm{r} / \mathrm{min}, 140 \mathrm{r} / \mathrm{min}, 160 \mathrm{r} / \mathrm{min}$, and $180 \mathrm{r} / \mathrm{min}$ (i.e., $1.7 \mathrm{~Hz}, 2.0 \mathrm{~Hz}, 2.3 \mathrm{~Hz}, 2.7 \mathrm{~Hz}, 3.0 \mathrm{~Hz}$ ) based on the vibration performance test of the shaking system. In this field trial, both sides of the selected 15 twelve-year-old trees in each row were harvested continuously. With one tree as a sample, each test contained 15 samples for the harvesting test under one hydraulic motor speed, namely a certain shaking frequency. After the end of each canopy shaking operation on the two sides of each row, the amount of detached oranges and dropped debris excluding the loss of dry or withered branches were collected and weighed for each tree. Also, all the fruits that had not been detached on the tree were manually picked and weighed. The fruit removal percentage $(F R P)$ was calculated by the following methodology (Equation (4)) reported by previous studies ${ }^{[36,38]}$. The tree damage rate $(T D R)$ during the mechanical harvesting process was defined as the percentage of the collected fresh debris including the leaves, branches and limbs based on the total weight of dropped oranges and debris ${ }^{[36]}$, as given by Equation (5): 


$$
\begin{aligned}
& F R P=\frac{M_{d o}}{M_{d o}+M_{u o}} \times 100 \% \\
& T D R=\frac{M_{d d}}{M_{d d}+M_{d o}} \times 100 \%
\end{aligned}
$$

where, FRP is the fruit removal percentage, \%; TDR is the proportion of debris load, \%; $M_{d o}$ is the mass of the detached oranges, $\mathrm{kg} ; M_{u o}$ is the mass of the un-detached oranges on the tree, $\mathrm{kg} ; M_{d d}$ is the mass of the dropped debris, $\mathrm{kg}$.

On the other hand, shaking duration also has significant influence on the fruit removal efficiency and tree damage ${ }^{[40,41]}$. In this study, the duration of the continuous canopy shaking for each tree was determined by the driving speed and the tree canopy size, which was calculated using the following equation:

$$
T_{s}=\frac{D_{T}}{v_{G}}
$$

where, $T_{S}$ is the shaking duration, $\mathrm{s} ; v_{G}$ is the driving speed, $\mathrm{m} / \mathrm{s} ; D_{T}$ is the largest diameter of the tree canopy as shown in Figure 1b, $\mathrm{m}$.

The total 15 groups of field tests were carried out under five shaking frequencies with three approximate driving speeds: $1 \mathrm{~km} / \mathrm{h}$, $3 \mathrm{~km} / \mathrm{h}$ and $5 \mathrm{~km} / \mathrm{h}$, respectively. Different driving speeds mean different shaking durations. Table 1 showed that the mean values of the tree canopy diameter was $2.94 \mathrm{~m}$, measured in section 2.1 .

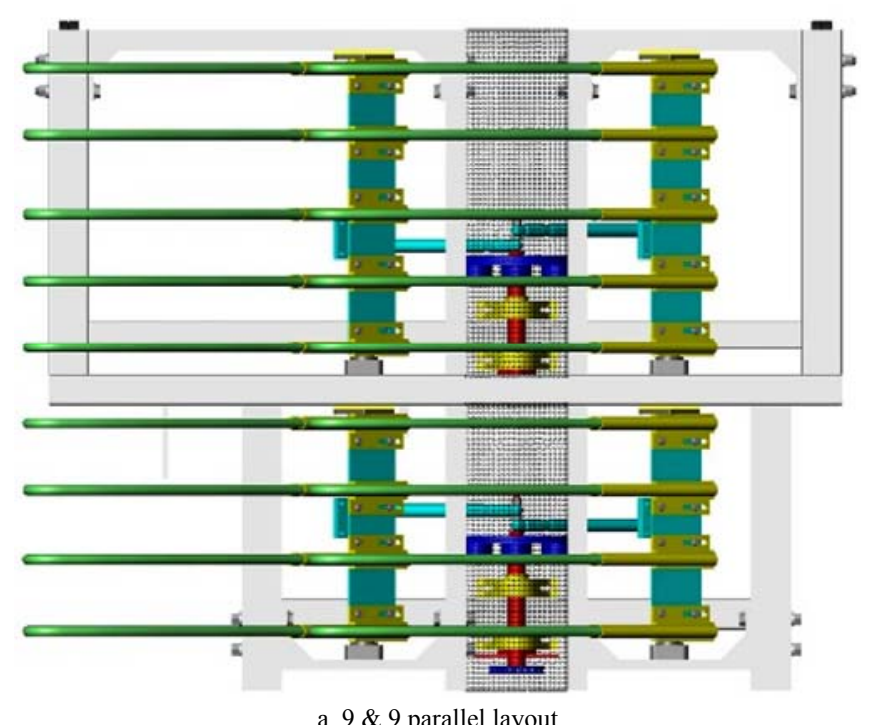

Accordingly, the shaking durations were $10.6 \mathrm{~s}, 3.5 \mathrm{~s}$, and $2.1 \mathrm{~s}$, respectively.

\subsection{Shaking rod layout investigation}

In addition to assessing the shaking frequency and duration, the shaking rod layout was also considered and investigated to obtain the optimal structure of the shaking system for a lower tree damage to the tree canopy. When the shaking system strikes the tree canopy, shaking rods produce a random vibration in the branches and detach fruits from the tree. The amount and distribution of the shaking rods could directly affect the vibration effectiveness. Figure 8 shows two types of shaking rod distribution in a staggered layout with $330 \mathrm{~mm}$ offset and parallel layout with $165 \mathrm{~mm}$ offset between the two shaking rods in the vertical direction. Another consideration was that investigating the performance of the shaking system with only one shaking rod has no significance for shaking the whole tree. Therefore, field tests were conducted using several shaking rods on two rows under these two rod distribution layouts, respectively. In this field trial, 15 twelve-year-old trees in each row were selected to be harvested continuously. The harvesting tests were carried out with the hydraulic motor speed of $160 \mathrm{r} / \mathrm{min}$ (i.e., $2.7 \mathrm{~Hz}$ ) under the driving speed of $3 \mathrm{~km} / \mathrm{h}$. The tree damage rate and fruit removal efficiency were investigated by the same methodology in Section 3.3 and calculated using Equations (4) and (5).

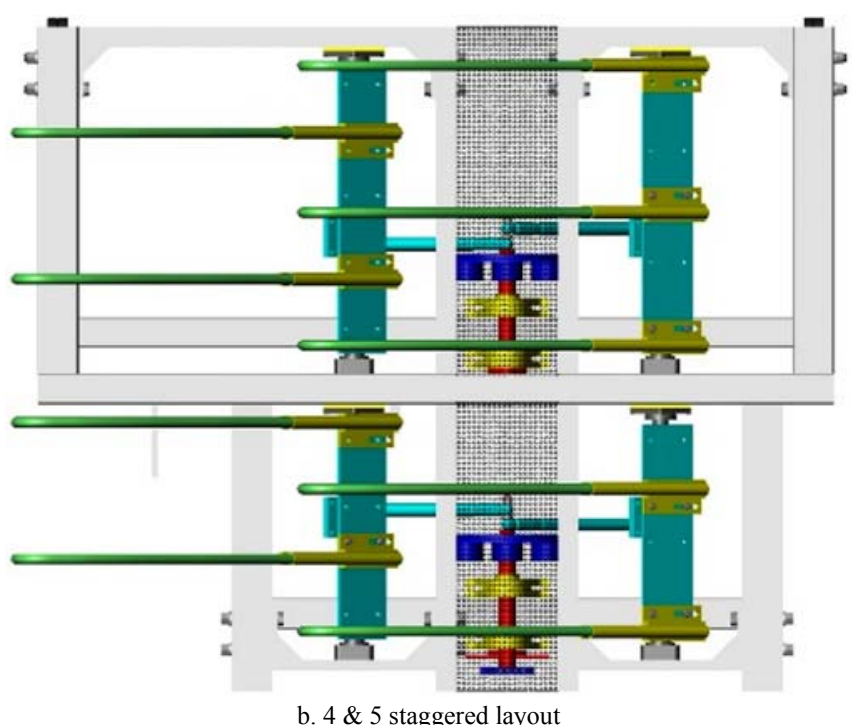

Note: $9 \& 9$ parallel layout means the shaking system used nine front and nine rear shaking rods; $4 \& 5$ staggered layout means the shaking system used five front shaking rods and four rear shaking rods.

Figure 8 Schematic diagrams of the shaking rod distribution

\subsection{Combined shaking frequencies of the top and bottom shaking systems}

The above performance investigations were conducted using the top and bottom shaking system with the same frequency. One of the main goals of this study was to evaluate the novel two-section canopy shaking system which can operate independently at variable frequencies. Therefore, studying the combination of the top and bottom shaking systems under different shaking frequencies is very important for evaluating the performance of the designed two-section canopy shaker. In order to investigate the optimal combined frequencies of the top and bottom shaking system, seven groups of the combined shaking frequencies were determined as shown in Table 4. The field tests were conducted using the developed prototype with the staggered shaking rod distribution under a tractor speed of $3 \mathrm{~km} / \mathrm{h}$. It should be pointed out that the same combined shaking frequencies (i.e., $4.1 \mathrm{~Hz} \& 4.1$
$\mathrm{Hz}, 4.7 \mathrm{~Hz} \& 4.7 \mathrm{~Hz}$ and $6.8 \mathrm{~Hz} \& 6.8 \mathrm{~Hz}$ ) were investigated in Section 3.3. Therefore, the other four groups of different combined shaking frequencies were carried out in this field tests. The canopy shaker using each combined shaking frequency harvested 15 trees in each row continuously. Fruit removal percentage and tree damage rate as two evaluation criteria were used to determine the optimal frequency combination of the top and bottom shaking system, which were calculated using the same methodology as in Section 3.3, as given by Equations (4) and (5).

Table 4 Combination of the shaking frequencies

\begin{tabular}{cccc}
\hline Items & \multicolumn{3}{c}{ Values } \\
\cline { 3 - 4 } \cline { 3 - 4 } Shaking frequency/Hz & 4.1 & 4.7 & 6.8 \\
\hline \multirow{2}{*}{\cline { 2 - 4 } Combined frequencies/Hz } & $4.1 \& 4.1$ & $4.7 \& 4.1$ & - \\
& $4.1 \& 4.7$ & $4.7 \& 4.7$ & $6.8 \& 4.7$ \\
& - & $4.7 \& 6.8$ & $6.8 \& 6.8$ \\
\hline
\end{tabular}




\section{Results and discussion}

\subsection{Variable vibration of the shaking mechanism through kinematic simulation}

Figure 9 shows that the linked crank-rocker mechanism with front and rear shaking rods can produce variable angular acceleration and velocity under a constant actuating speed of $120 \mathrm{r} / \mathrm{min}$. Simulation results indicate that the front and rear shaking rods induce a differential motion periodically with different vibrating speeds along with the rotating of flywheel. Figure 9a shows that there are two maximum values of the angular acceleration with opposite direction during each period for both shaking rods. Thus, each shaking rod would strike the tree canopy two times with higher force during each period based on Newton's Second Law of Motion $^{[42]}$ as a vector Equation (7). Therefore, the linked crank-rocker mechanism with front and rear shaking rods would forcefully shake the tree canopy four times during each period. In Figure $9 \mathrm{~b}$, it is observed that the angular velocity of the shaking rod has one sharp and slow change during each period, which indicates that the shaking rod could produce a greater speed change in a shorter time period during the return stroke. It also reflects the quick-return characteristics of the crank-rocker mechanism. According to the Theorem of Momentum $^{[43]}$ as a vector Equation (8), each shaking rod could produce a greater impact force on the tree canopy during the return stroke period.

$$
\begin{aligned}
\overrightarrow{\boldsymbol{F}} & =m \overrightarrow{\boldsymbol{a}} \\
\overrightarrow{\boldsymbol{F}} t & =m \Delta \overrightarrow{\boldsymbol{v}}
\end{aligned}
$$

where, $\overrightarrow{\boldsymbol{F}}$ is resultant force of the shaking rod striking the tree canopy, $\mathrm{N} ; \overrightarrow{\boldsymbol{a}}$ is resultant angular acceleration of the shaking rod, $\mathrm{rad} / \mathrm{s}^{2} ; \Delta \overrightarrow{\boldsymbol{v}}$ is the angular velocity variation during the time of $t$, $\mathrm{rad} / \mathrm{s}$.

The above simulation results showed that the tree canopy would be forcefully vibrated by the front and rear shaking rods during each vibration period. Therefore, it indicated that this designed canopy shaking mechanism could effectively make forceful vibrations on the tree canopy.

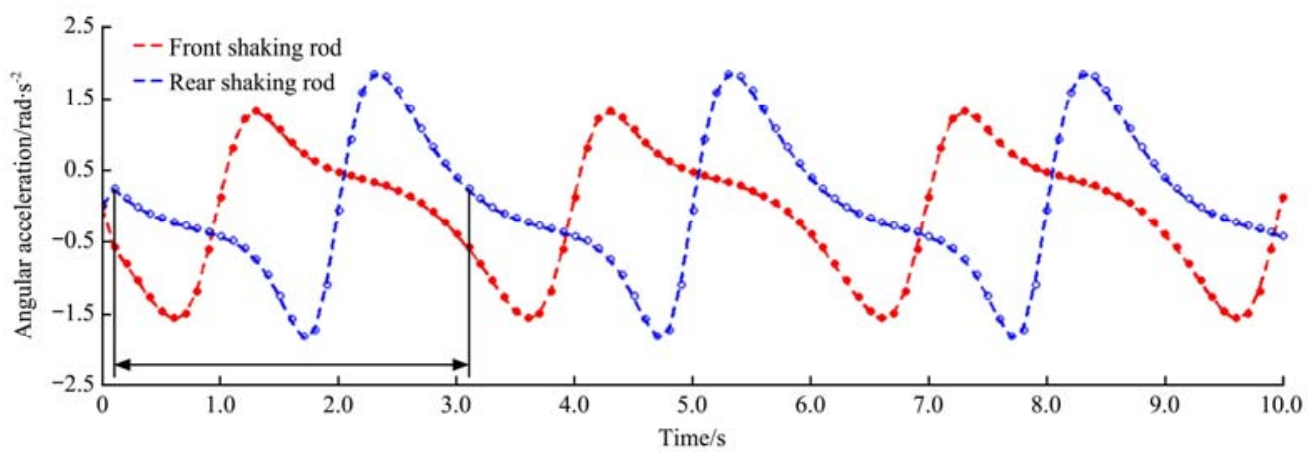

a. Angular acceleration of the front and rear shaking rods

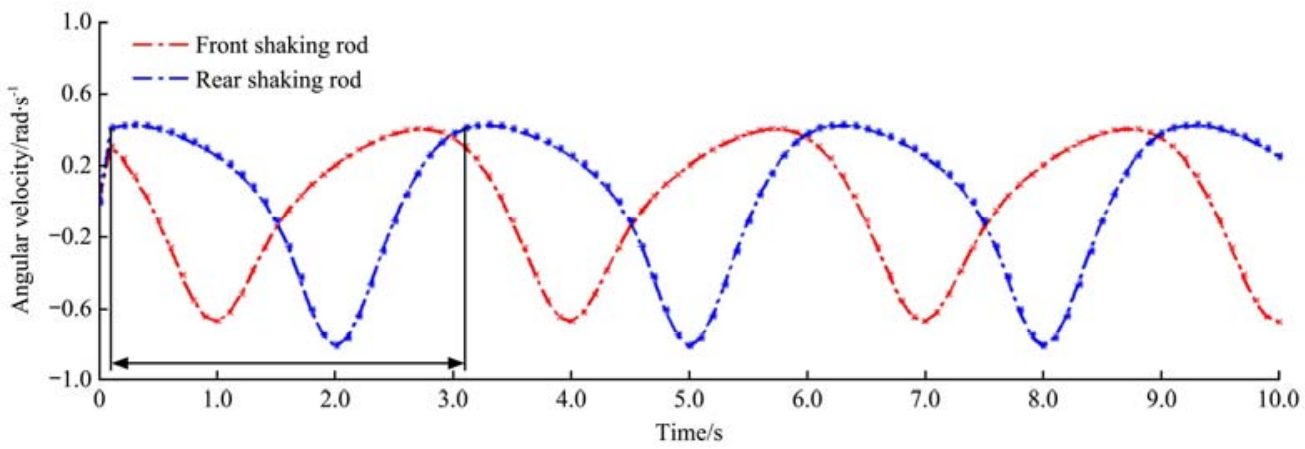

b. Velocity variation of the front and rear shaking rods

Figure 9 Kinematic simulation results of the shaking mechanism

\subsection{Performance test of the shaking system}

Performance test of the shaking system was conducted before field trial. Shaking frequency and acceleration amplitude were obtained by analyzing the acceleration data through the computational algorithm in MATLAB environment. The results of the performance test were summarized in Table 5.

\begin{tabular}{|c|c|c|c|c|c|c|c|}
\hline \multirow{2}{*}{ Parameters } & \multicolumn{7}{|c|}{ Hydraulic motor speed $/ \mathrm{r} \cdot \mathrm{min}^{-1}$} \\
\hline & 60 & 80 & 100 & 120 & 140 & 160 & 180 \\
\hline Motion frequency $/ \mathrm{Hz}$ & 1.0 & 1.3 & 1.7 & 2.0 & 2.3 & 2.7 & 3.0 \\
\hline Maximum frequency $/ \mathrm{Hz}$ & 3.3 & 3.7 & 4.1 & 4.9 & 5.8 & 6.2 & 8.8 \\
\hline Minimum frequency/Hz & 1.1 & 1.6 & 1.5 & 1.8 & 1.9 & 1.9 & 2.1 \\
\hline Shaking frequency $/ \mathrm{Hz}$ & $2.5 \pm 0.3$ & $2.9 \pm 0.4$ & $3.3 \pm 0.3$ & $3.6 \pm 0.3$ & $4.1 \pm 0.4$ & $4.7 \pm 0.4$ & $6.8 \pm 0.3$ \\
\hline
\end{tabular}

Table 5 Performance parameters of the shaking system

It can be observed that the shaking frequency and acceleration amplitude with mean and SD values rose at different rates along with the linear increase of motion frequency. The test results showed that the designed shaking system produced adjustable frequency from $2.5 \mathrm{~Hz}$ to $6.8 \mathrm{~Hz}$ under a series of operated hydraulic motor speeds. Besides, each operated hydraulic motor 
speed produced a variable frequency range, which was different from the existing canopy shakers striking the entire tree canopy at a fixed frequency ${ }^{[10,24,27]}$. It is clear that shaking frequency and acceleration amplitude increased significantly when the rotation speed increased from $160 \mathrm{r} / \mathrm{min}$ to $180 \mathrm{r} / \mathrm{min}$. This result indicates that the higher motion frequency can produce stronger vibration with higher shaking acceleration, which is similar to previous reports $^{[12,21,22]}$. In addition, it can be seen that this designed shaking system allows for frequency to vary under different hydraulic motor speeds. Compared to the motion frequency, the variation of the shaking frequency was most likely caused by the elastic deformation of the flexible shaking rod. The shaking rod deformation characteristics are not within the scope of this study, but its shaking response could potentially relate to the variable frequency and amplitude ${ }^{[36]}$. Due to ineffective shaking for fruits harvesting under a low shaking frequency, which has been observed by Ortiz and Torregrosa ${ }^{[41]}$, all of the subsequent field trials for harvesting efficiency and tree damage assessment were performed with the shaking frequency range from $3.3 \mathrm{~Hz}$ to $6.8 \mathrm{~Hz}$, which has been recommended for canopy shakers ${ }^{[45]}$.

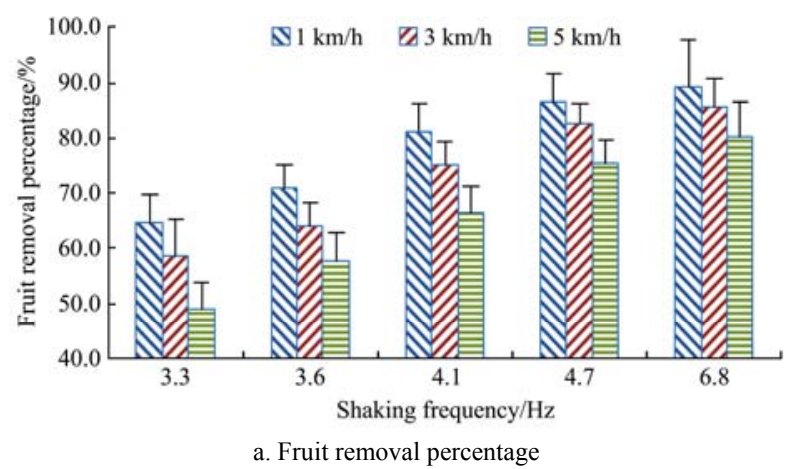

\subsection{Fruit removal and tree damage evaluation}

4.3.1 Effects of shaking frequency on fruit removal percentage and tree damage rate

In this study, tractor driving speed and shaking frequency of the shaking system are the two primary factors that can be directly related to fruit harvesting and tree damage. Figure 10 shows the mean and SD values of the fruit removal percentage and tree damage rate under different shaking frequencies and driving speeds. For all of the fruit removal percentages, the mean values under three different driving speeds had similar trends that higher shaking frequencies could remove more fruits, which agree with previous studies reported by Hong et al. ${ }^{[27]}$ and Castro-Garcia et al. ${ }^{[44]}$, but the fruit removal percentage changed slightly when the shaking frequency reached $4.7 \mathrm{~Hz}$. Additionally, it was observed that the fruit removal percentage at lower driving speed could be higher, which is similar to the results of previous studies that reasonable shaking duration produces more fruit removal ${ }^{[40,41,45,46]}$. Shamshiri et al. ${ }^{[39]}$ also pointed out that the reduction of driving speed has a negative effect on the efficiency of the harvester and may make uneconomical mechanical harvesting.

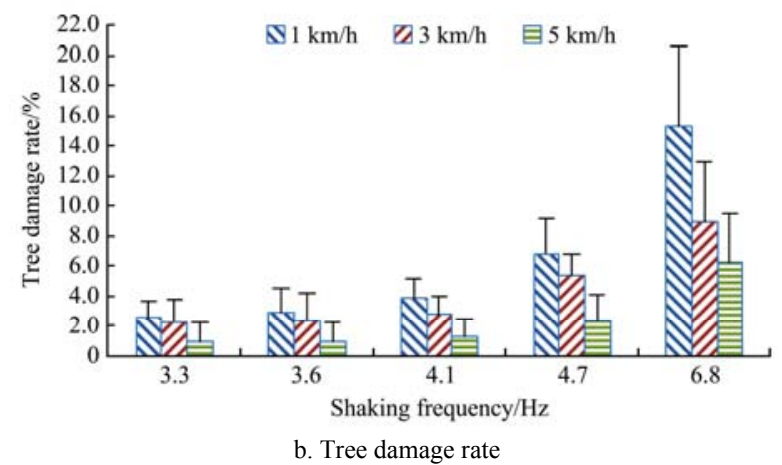

Figure 10 Mean and SD values of fruit removal percentage and tree damage rate under different driving speeds and shaking frequencies

Besides, the tree damage rate also increased when the shaking frequency was raised, but the highest shaking frequency of $6.8 \mathrm{~Hz}$ only marginally detached more fruit compared to the shaking frequency of $4.7 \mathrm{~Hz}$. Conversely, all of the tree damage rates under the three driving speeds increased rapidly when the shaking frequency reached $4.7 \mathrm{~Hz}$. In addition, the tree damage rate under the driving speed of $5 \mathrm{~km} / \mathrm{h}$ was lower than that of other two driving speeds, which indicates that shorter shaking duration can produce less tree damage. Namely, slow driving speeds cause lengthy shaking durations beyond the optimal value but cannot significantly increase the fruit removal percentage while producing more serious tree damage, which is in accordance with the previous reports $^{[38,46]}$.

Specifically, the shaking system operated with a shaking frequency of $6.8 \mathrm{~Hz}$ and a tractor speed of $1 \mathrm{~km} / \mathrm{h}$ caused more tree damage of almost $16 \%$ with large standard deviations, even though a relative high fruit removal percentage can be obtained, i.e. up to $90 \%$. In addition, the tree damage rate was similar around $3 \%$ under the lower shaking frequency between $3.3 \mathrm{~Hz}$ and $4.1 \mathrm{~Hz}$, but a lower fruit removal percentage was also obtained. Combining the advantages and weaknesses of both fruit removal percentage and tree damage rate, there was a compromising solution, i.e. operating with a shaking frequency of $4.7 \mathrm{~Hz}$ at a driving speed of $3 \mathrm{~km} / \mathrm{h}$ which obtained a fruit removal percentage of $82.6 \%$ and a tree damage rate of $5.4 \%$.

Overall, a canopy shaking system can obtain a harvesting rate 15 times higher than manual harvesting ${ }^{[13]}$. Compared with the existing continuous canopy shaker with a maximum harvesting efficiency of 400 trees per hour which has been reported by Roka et al. ${ }^{[9]}$, this developed canopy shaker achieved a similar or higher harvesting efficiency between 360 and 500 trees per hour under an approximate driving speed of $3 \mathrm{~km} / \mathrm{h}$. However, the fruit removal percentage of $82.6 \%$ is still lower compared to the feasible mechanical harvesting with high fruit removal percentage (> 85\%) which has been recommended by Castro-Garcia et al. ${ }^{[44]} \mathrm{A}$ probable reason is that the fruits were difficult to be detached in the central area where the shaking rods could not reach. Therefore, using longer shaking rods and optimized structural parameters could be the potential solution in future works to obtain a higher fruit removal percentage. On the other hand, Spann and Danyluk $^{[23]}$ investigated the debris load based on the total sample weight employing two canopy shaking systems (Oxbo 3210 and Oxbo 3220) for citrus harvesting, found that the proportion of debris load was up to $12 \%$ and $9 \%$, respectively. The comparison indicates that this novel canopy shaker is feasible and effective to reduce tree damage for mehcanical citrus harvesting.

4.3.2 Effects of shaking rod layout on fruit removal percentage and tree damage rate

The shaking rod distribution determines the gap distance between the adjacent shaking rods which can directly affect the passing ability through the tree canopy. Comparatively, this capacity of the shaking system could influence the fruit removal percentage and tree damage rate. In this study, the 4 \& 5 staggered layout and $9 \& 9$ parallel layout were defined as the two types of shaking rod distributions. Harvesting operations with a driving speed of $3 \mathrm{~km} / \mathrm{h}$ and a shaking frequency of $4.7 \mathrm{~Hz}$ were 
carried out to evaluate the performance of the two shaking rod layouts. A summary of the fruit removal percentage and tree damage rate estimated from the field test data is reported in Table 6. It is clear that the two types of shaking rod distributions obtained a similar fruit removal percentage of $82.6 \%$ and $83.5 \%$, respectively, but the $9 \& 9$ parallel layout caused a much higher tree damage rate up to $7.5 \%$. By contrast, the $4 \& 5$ staggered layout was more reasonable to reduce tree damage and maintain a higher harvesting efficiency. A probable reason is that the flexible shaking rod configured in a staggered distribution has a better passing ability. The results demonstrated that the staggered distribution of the shaking rod could effectively adapt to the random spatial distribution of the whole tree canopy and relieve tree damage.

Table 6 Fruit removal percentage and tree damage rate under different shaking rod layout

\begin{tabular}{lccc}
\hline \multirow{2}{*}{ Parameters } & $4 \& 5$ staggered layout & & $9 \& 9$ parallel layout \\
\cline { 2 - 2 } & Mean values and SD & & Mean values and SD \\
\hline Fruit removal percentage $/ \%$ & $82.6 \pm 3.8$ & $83.5 \pm 2.2$ \\
Tree damage rate $/ \%$ & $5.4 \pm 1.4$ & $7.5 \pm 0.7$ \\
\hline
\end{tabular}

4.3.3 Effects of the combined shaking frequency on fruit removal percentage and tree damage rate

Fruit removal percentage and tree damage rate are the two most important indicators by which to evaluate the performance of the canopy shaker during mechanical harvesting. Table 7 represents the mean and SD values of the fruit removal percentage and its corresponding tree damage rate calculated from field test data under seven groups of combined operating shaking frequencies. It can be observed that the fruit removal percentage is similar around $81.8 \%$ and $82.5 \%$ when the combined shaking frequency is $4.1 \mathrm{~Hz} \& 4.7 \mathrm{~Hz}$ and $4.7 \mathrm{~Hz} \& 4.1 \mathrm{~Hz}$ of the top and bottom shaking system, respectively. Comparatively, tree damage would be affected more intensively under different combined shaking frequencies. It was also found that the fruit removal percentage increased slightly while producing a rapid growth in tree damage when the shaking frequency was increased from $4.7 \mathrm{~Hz}$ to $6.8 \mathrm{~Hz}$. In particular, the shaking frequency combination of $4.7 \mathrm{~Hz}$ \& $4.1 \mathrm{~Hz}$ can obtain a low tree damage rate of $3.9 \%$ and a relative high fruit removal percentage of $82.5 \%$. Similarly, the shaking frequency combination of $6.8 \mathrm{~Hz} \& 4.7 \mathrm{~Hz}$ can produce a relatively low tree damage rate of $7.6 \%$ and also obtain a comparative high fruit removal percentage of $84.9 \%$. Besides, the coefficient of variation of both fruit removal percentage and tree damage rate is minimal when the combined shaking frequency is $4.7 \mathrm{~Hz} \& 4.1 \mathrm{~Hz}$. It means that the fruit removal percentage and tree damage are more homogeneous under this combined shaking frequency. By contrast, the tree damage was significantly reduced when the shaking frequency of the top shaking system was higher than that of bottom shaking system. The results indicate that the top and bottom shaking system, with higher and lower shaking frequency combination, can result in less tree damage while maintaining a relatively higher fruit removal percentage.

Table 7 Fruit removal percentage and tree damage rate under different combined frequencies

\begin{tabular}{|c|c|c|c|c|c|c|c|}
\hline \multirow{2}{*}{$\begin{array}{l}\text { Group } \\
\text { number }\end{array}$} & \multirow{2}{*}{$\begin{array}{l}\text { Combined } \\
\text { frequency } / \mathrm{Hz}\end{array}$} & \multicolumn{3}{|c|}{ Fruit removal percentage $/ \%$} & \multicolumn{3}{|c|}{ Tree damage rate $/ \%$} \\
\hline & & Mean value & Standard deviation & Coefficient of variation & Mean value & Standard deviation & Coefficient of variation \\
\hline 1 & $4.1 \& 4.1$ & $75.0^{\mathrm{c}}$ & 4.3 & 0.06 & $2.8^{\mathrm{d}}$ & 1.2 & 0.45 \\
\hline 2 & $4.1 \& 4.7$ & $81.8^{\mathrm{b}}$ & 2.8 & 0.03 & $5.3^{\mathrm{c}}$ & 1.3 & 0.25 \\
\hline 3 & $4.7 \& 4.1$ & $82.5^{\mathrm{b}}$ & 2.9 & 0.03 & $3.9^{\mathrm{d}}$ & 0.6 & 0.14 \\
\hline 4 & $4.7 \& 4.7$ & $82.6^{b}$ & 3.8 & 0.05 & $5.4^{\mathrm{c}}$ & 1.4 & 0.26 \\
\hline 5 & $4.7 \& 6.8$ & $84.4^{\mathrm{a}}$ & 4.0 & 0.05 & $8.5^{\mathrm{a}}$ & 2.3 & 0.27 \\
\hline 6 & $6.8 \& 4.7$ & $84.9^{\mathrm{a}}$ & 4.7 & 0.05 & $7.6^{\mathrm{b}}$ & 1.9 & 0.24 \\
\hline 7 & $6.8 \& 6.8$ & $85.7^{\mathrm{a}}$ & 5.1 & 0.06 & $9.0^{\mathrm{a}}$ & 4.0 & 0.45 \\
\hline
\end{tabular}

Note: Different letters for fruit removal percentage and tree damage rate indicate significant differences under different frequency combinations $(p<0.05)$.

In conclusion, the combined shaking frequency of $4.7 \mathrm{~Hz} \&$ $4.1 \mathrm{~Hz}$ of the top and bottom shaking system within a frequency range from $1.9 \mathrm{~Hz}$ to $6.2 \mathrm{~Hz}$ listed in Table 5 would be the optimal operating parameters for the citrus canopy shaker. This frequency range agrees with the conclusions which have been reported by Savary et al. ${ }^{[21]}$ and Castro-Garcia et al. ${ }^{[37,47]}$. It also indicated that the two-section canopy shaker with an optimal frequency combination could be adaptable to the top and bottom zone of the tree canopy, to obtain less tree damage and an acceptable fruit removal percentage.

\section{Conclusions}

In this study, a two-section canopy shaking system based on a linked crank-rocker mechanism with top and bottom shaking units was designed and developed. Each shaking unit has front and rear shaking rods configured in a staggered distribution. The reciprocating motion of the shaking rod based on the vibration mechanism was simulated and analyzed. The shaking frequency and acceleration of the shaking rod can be easily adjusted by controlling the speed of the hydraulic motor through a flow control valve. The performance of the canopy shaking system concerning fruit removal percentage and tree damage level was conducted by field trials under different conditions, including combined shaking frequencies, shaking duration, shaking rod layout and so on. From the results of the actual harvesting test in the field, the major achievements of this research can be summarized as follows:

1) The linked crank-rocker mechanism with quick-return characteristics and differential property produced variable frequency from $3.3 \mathrm{~Hz}$ to $6.8 \mathrm{~Hz}$, which could effectively striking the tree canopy with reciprocating motion.

2) In the test performed with the shaking frequency of $4.7 \mathrm{~Hz}$, there is a compromise solution operated at the driving speed of $3 \mathrm{~km} / \mathrm{h}$ which had an acceptable fruit removal percentage of $82.6 \%$ and a lower tree damage rate of $5.4 \%$.

3) Staggered distribution with larger intervals of the shaking rods could effectively adapt to the irregular spatial distribution of the whole tree canopy for reducing tree damage.

4) In the case of the shaking frequency combination of the two-section canopy shaking system, the top and bottom section with higher and lower shaking frequencies respectively can result in less tree damage while maintaining a relative high fruit removal percentage. 
This novel two-section canopy shaker with variable frequency is feasible and adaptable to reduce tree damage and increase fruit removal for mehcanical citrus harvesting, but it also has some limitations, such as limited vibration area and comparatively lower fruit removal percentage $(<85 \%)$. Therefore, the shaking mechanism structure and operating parameters should be optimized in future work to obtain a higher fruit removal percentage, create less tree damage, and also adapt to the potential use of bigger harvesters. Furthermore, this canopy shaking system can be equipped with a fruit catching frame and conveying components to collect and transport the detached fruits continuously.

\section{Acknowledgements}

The authors greatly appreciate the Citrus Initiatives of Florida for providing the funding of this research. We are also grateful to the China Scholarship Council for providing the financial support to the author $\mathrm{Y} . \mathrm{Pu}$ for conducting his collaborative doctoral research in the CREC at the University of Florida. Additional financial supports are also provided from the National Key R\&D Program of China "the 13th Five-Year Plan" (Program No. 2016YFD0700503), Major Program of Cooperative Innovation for Yangling Demonstration Zone (Program No. 2016CXY-20), and the Shaanxi Provincial Agricultural Technology Program of Innovation and Development (Program No. 2016NY-127). Besides, we are grateful for the suggestions and field test assistance provided by Roy Sweeb, Dr. Jaafar Abdulridha and Saman Souri. Also, we thank the critical comments and suggestions from the anonymous reviewers for improving the manuscript.

\section{[References]}

[1] FAOSTAT. Crops statistical databases. 2016. http://www.fao.org/ faostat/en/\#data. Accessed on [2018-07-10].

[2] USDA-NASS. Citrus statistics 2015-2016. D.C.: USDA, National Agricultural Statistics Service, Florida Field Office. 2017. https://www.nass.usda.gov/Statistics_by_State/Florida/Publications/Citrus/. Accessed on [2017-08-26]

[3] Sanders K F. Orange harvesting systems review. Biosyst Eng, 2005; 90(2): 115-125.

[4] Roka, F M, Hyman B R. Measuring productivity of citrus hand harvesters and assessing implications on harvest costs and mechanical harvesting developments. Gainesville: University of Florida Institute of Food and Agricultural Sciences, 2013. http://edis.ifas.ufl.edu/fe933. Accessed on [2018-07-21]

[5] Calvin, L, Martin, P. The U.S. produce industry and labor: Facing the future in a global economy. D.C.: USDA Economic Research Service, 2010. https://www.ers.usda.gov/publications/pub-details/?pubid=44766. Accessed on [2017-08-02]

[6] Li P L, Lee S H, Hsu H Y. Review on fruit harvesting method for potential use of automatic fruit harvesting systems. Procedia Engineering, 2011; 23: 351-366

[7] Coppock G E. Picking citrus fruit by mechanical means. Proc Flo State Hort Soc, 1961; 74: 247-251.

[8] Roka F M, Ehsani R J, Futch S H, Hyman B R. Citrus mechanical harvesting systems-Trunk shakers. Florida:Food and Economic Resources Department, 2014; UF/IFAS Extension.

[9] Roka F M, Ehsani R J, Futch S H, Hyman B R. Citrus mechanical harvesting systems-Continuous canopy shakers. Florida: Food and Economic Resources Department, 2014; UF/IFAS Extension.

[10] Whitney J D. Field test results with mechanical harvesting equipment in Florida oranges. Appl Eng Agric, 1999; 15(3): 205-210.

[11] Sumner H R. Selective harvesting of valencia oranges with a vertical canopy shaker. T Asae, 1973; 16(6): 1024-1026.

[12] Castro-Garcia S, Rosa U A, Gliever C J, Smith D, Burns J K, Krueger W H, et al. Video evaluation of table olive damage during harvest with a canopy shaker. Horttechnology, 2009; 19(2): 260-266.

[13] Sola-Guirado R R, Castro-Garcia S, Blanco-Roldan G L, Jimenez-Jimenez F, Castillo-Ruiz F J, Gil-Ribes J A. Traditional olive tree response to oil olive harvesting technologies. Biosyst Eng, 2014; 118: 186-193.

[14] Sola-Guriado R R, Blanco-Roldan G L, Gil-Ribes J A. New harvester machine for traditional olive orchards: agronomic and industrial engineering. Dyna-Bilbao, 2018; 93(1): 60-66.

[15] Lang Z. Lincoln canopy apple harvester using a continuous horizontal shaking method. J Agr Eng Res, 1989; 44(4): 267-273.

[16] Ferreira L D, da Silva F M, Ferreira D D, Sales R S. Recommendation for mechanical harvesting of coffee based on vibration behavior settings rods harvesters. Cienc Rural, 2016; 46(2): 273-278.

[17] Caprara C, Pezzi F. Measuring the stresses transmitted during mechanical grape harvesting. Biosyst Eng, 2011; 110(2): 97-105.

[18] Yu P C, Li C Y, Takeda F, Krewer G, Rains G, Hamrita T. Measurement of mechanical impacts created by rotary, slapper, and sway blueberry mechanical harvesters. Comput Electron Agr, 2014; 101: 84-92.

[19] Brown G K. New mechanical harvesters for the Florida citrus juice industry. Horttechnology, 2005; 15(1): 69-72.

[20] Whitney J. Performance of mechanical citrus harvesters in Florida. Proceedings of the International Society of Citriculture, 2000; 277-279.

[21] Savary S K J U, Ehsani R, Schueller J K, Rajaraman B P. Simulation study of citrus tree canopy motion during harvesting using a canopy shaker. Trans of the ASABE, 2010; 53(5): 1373-1381.

[22] Pezzi F, Caprara C. Mechanical grape harvesting: Investigation of the transmission of vibrations. Biosyst Eng, 2009; 103(3): 281-286.

[23] Spann T M, Danyluk M D. Mechanical harvesting increases leaf and stem debris in loads of mechanically harvested citrus fruit. Hortscience, 2010; 45(8): 1297-1300.

[24] Gupta S K, Ehsani R, Kim N H. Optimization of a citrus canopy shaker harvesting system: Mechanistic tree damage and fruit detachment models. Trans of the ASABE, 2016; 59(4): 761-776.

[25] Roka, F M, House L A, Mosley K R. Mechanically harvesting sweet orange trees in Florida: Addressing grower concerns about production and long-term tree health.Gainesville: University of Florida Institute of Food and Agricultural Sciences, 2014. Available at: http://edis.ifas.ufl.edu/ fe949. Accessed on [2018-07-21]

[26] Coppock G E. Properties of young and mature'Valencia'oranges related to selective harvest by mechanical means. Trans of the ASAE, 1972; 15(2): 0235-0238.

[27] Hong M Y, Rosa U A, Upadhyaya S K. Optimum operating parameters for a rotary drum shaker for harvesting jatropha curcas $\mathrm{L}$. Trans of the ASABE, 2012; 55(6): 2051-2058.

[28] Sola-Guirado R R, Blanco-Roldan G L, Castro-Garcia S, Castillo-Ruiz F J, Gil-Ribes J A. Innovative circular path harvester for mechanical harvesting of irregular and large-canopy olive trees. Int J Agric \& Biol Eng, 2018; 11(3): 86-93.

[29] Chen D, Du X Q, Wang S M, Zhang Q. Mechanism of vibratory fruit harvest and review of current advance. Transactions of the CSAE, 2011; 27(8): 195-200. (in Chinese)

[30] Du X Q, Wu C Y, He L Y, Tong J H. Dynamic characteristics of dwarf Chinese hickory trees under impact excitations for mechanical fruit harvesting. Int J Agric \& Biol Eng, 2015; 8(1): 17-25.

[31] Whitney J, Wheaton T. Tree spacing affects citrus fruit distribution and yield. Proc Fla State Hort Soc, 1984; 97: 44-47.

[32] Peterson D. Mechanical harvester for process oranges. Appl Eng Agric, 1998; 14(5): 455-458.

[33] Gupta S K, Ehsani R, Kim N H. Optimization of a citrus canopy shaker harvesting system: Properties and modeling of tree limbs. Trans of the ASABE, 2015; 58(4): 971-985.

[34] Lun M, Leu Y H. Design of crank-rocker mechanisms with optimum transmission angle over working stroke. Mech Mach Theory, 1996; 31(4) 501-511.

[35] Fan Y X, Zhang Q. Machine theory and mechanical design. In Chapter 4: Planar Linkage Mechanisms. Beijing: Qinghua University Press, 2014. pp: 47-73. (in Chinese)

[36] Pu Y J, Toudeshki A, Ehsani R, Yang F Z, Abdulridha J. Selection and experimental evaluation of shaking rods of canopy shaker to reduce tree damage for citrus mechanical harvesting. Int J Agric \& Biol Eng, 2018; 11(2): 48-54.

[37] Castro-Garcia S, Blanco-Roldan G L, Ferguson L, Gonzalez-Sanchez E J, Gil-Ribes J A. Frequency response of late-season 'Valencia' orange to selective harvesting by vibration for juice industry. Biosyst Eng, 2017; 155: 77-83.

[38] Leone A, Romaniello R, Tamborrino A, Catalano P, Peri G. Identification of vibration frequency, acceleration, and duration for 
efficient olive harvesting using a trunk shaker. Trans of the ASABE, 2015; 58(1): 19-26.

[39] Shamshiri, R, Ehsani, R, Maja, J M, Roka, F M. Determining machine efficiency parameters for a citrus canopy shaker using yield monitor data. Applied engineering in Agriculture, 2013; 29(1): 33-41.

[40] Zhou J, He L, Zhang Q, Du X, Chen D, Karkee M. Evaluation of the influence of shaking frequency and duration in mechanical harvesting of sweet cherry. Appl Eng Agric, 2013; 29(5): 607-612.

[41] Ortiz C, Torregrosa A. Determining adequate vibration frequency, amplitude, and time for mechanical harvesting of fresh mandarins. $\mathrm{T}$ ASABE, 2013; 56(1): 15-22.

[42] Willis J R, Milton G W. On modifications of Newton's second law and linear continuum elastodynamics. Proceedings of the Royal Society A: Mathematical, Physical and Engineering Sciences, 2007; 463(2079): $855-880$
[43] Yunt K. The impulsive action integral for rigid-body mechanical systems with impacts. J Comput Nonlin Dyn, 2012; 7(3): 636-647.

[44] Castro-Garcia S, Blanco-Roldán G L, Ferguson L, González-Sánchez E J, Gil-Ribes J A. Frequency response of late-season 'Valencia' orange to selective harvesting by vibration for juice industry. Biosyst Eng, 2017; 155: 77-83.

[45] Burns J K, Buker R S, Roka F M. Mechanical harvesting capacity in sweet orange is increased with an abscission agent. Horttechnology, 2005; 15(4): 758-765.

[46] Blanco-Roldan G L, Gil-Ribes J A, Kouraba K, Castro-Garcia S. Effects of trunk shaker duration and repetitions on removal efficiency for the harvesting of oil olives. Appl Eng Agric, 2009; 25(3): 329-334.

[47] Castro-Garcia S, Sola-Guirado R R, Gil-Ribes J A. Vibration analysis of the fruit detachment process in late-season 'Valencia' orange with canopy shaker technology. Biosyst Eng, 2018; 170: 130-137. 